\title{
Epidemiology of hip and groin injuries in Swedish male first football league
}

\author{
Filip Lundgårdh ${ }^{1} \cdot$ Kjell Svensson ${ }^{2} \cdot$ Marie Alricsson $^{3}[$
}

Received: 7 November 2018 / Accepted: 4 March 2019 / Published online: 20 March 2019

(c) The Author(s) 2019

\begin{abstract}
Purpose This study aimed to investigate the incidence, pattern, and burden of hip/groin injuries in Swedish professional male football players over five consecutive seasons.

Methods Injury history from 16 football teams in the Swedish male first football league was evaluated during five consecutive seasons. The team's medical staff recorded team exposure and time-loss injuries prospectively between 2012 and 2016. Results In total, 467 time-loss injuries located in the hip/groin area were recorded among 1,687 professional male football players, with an overall incidence and burden of $0.82 / 1,000 \mathrm{~h}$ and $15.6 / 1,000 \mathrm{~h}$, respectively. There appeared to be an increased risk of hip/groin injuries during the last two seasons (2015-2016); however, the difference was not statistically significant (n.s). Recurrent injury rate was relatively low (14\%), and overuse injuries accounted for the majority of injuries and absence days. Muscle injuries were the main injury type, while kicking and sprinting/running were the primary causes of injury. Goalkeepers had the lowest percentage of injuries and absence days.

Conclusion Hip/groin injuries are a substantial problem in football, but does not seem to be an increasing phenomenon in the Swedish male first football league. Index and overuse injuries accounted for the majority of injuries and absence days. Thus, the focus should be on preventing hip/groin injuries to lower the injury rate. These new findings should be taken into consideration when designing and implementing preventive training interventions.
\end{abstract}

Level of evidence II.

Keywords Burden $\cdot$ Incidence $\cdot$ Injury rate $\cdot$ Professional $\cdot$ Risk factors $\cdot$ Soccer

\section{Introduction}

The hip/groin is one of the most injury prone areas in football [7]. It constitutes approximately $11-17 \%$ of all injuries in professional football [37], with frequencies as high as $19 \%$ [32].

However, the hip/groin is, difficult to diagnose and treat due to the complexity of the region [38] and the lack of

Marie Alricsson

marie.alricsson@1nu.se

1 Department of Health Sciences, Swedish Winter Sport Research Centre, Mid Sweden University, Östersund, Sweden

2 Department of Molecular Medicine and Surgery, Stockholm Sports Trauma Research Centre, Karolinska Institutet, Stockholm, Sweden

3 Department of Sports Science, Linnaeus University, 39182 Kalmar, Sweden consensus statements [36]. As an example, Serner et al. [27] found 33 different diagnoses used in 72 studies, where most of the diagnostic criteria either were not reported or used in excess. Increasing interest in this specific area has resulted in recent consensus concerning standardisation of taxonomy and terminology $[13,35,36]$.

Epidemiological research in football is often described either during one season [2, 18], part of a season [3, 9], or comprised of rather small sample sizes [22]. Extensive research has been conducted in Europe and Scandinavia at club level, by focusing on injury incidence and injury pattern [32]. However, there are fewer studies concentrating on hip/groin injuries, where the focus has been on a selection of European teams [37, 38] or non-professionals $[20,31]$. Nonetheless, there was one recent study that used injury surveillance to describe hip/groin injuries in a professional league [23]. Despite the growing amount of hip/groin research in football, little is known about seasonal variations in professional league football. To the best of the author's 
knowledge, no previous study has investigated variations between seasons for an entire professional league.

The aim of the present cohort study was to investigate the incidence, pattern, and burden of hip/groin injuries in Swedish professional male football players over five consecutive seasons.

\section{Materials and methods}

The present cohort study of Swedish professional male football players was carried out over five consecutive seasons, from 2012 to 2016. The Swedish first football league consists of 16 teams annually. Over five seasons, there has been a total of 80 team seasons (2,299 players, age range 16-44), with 23 different teams competing. Four of these teams, equal to 400 players and 14 team seasons, have not collected data for the Swedish National Injury Surveillance Database [30] on annual basis and are, therefore, excluded in the present study. One team, equal to 154 players and five team seasons, did not submit their written consent in time for data extraction and is, consequently, excluded from the present study. Two teams, equivalent to 58 players and two team seasons, registered data between the 2012 and 2015 season and are accordingly included in those seasons in the present study.

Ethical approval was obtained from the Regional Ethical Review Board in Umeå, Sweden (2016/491-31), and the study was conducted in accordance with the Declaration of Helsinki for Human studies.

\section{Data collection}

A total of 59 team seasons were included, involving 16 different teams, with seven of the teams participating during all five seasons. Teams participated in a mean \pm SD of $3.7 \pm 1.5$ seasons (range 1-5). There were 1,687 players in total, with an average of 29 players per team (range 23-34), divided by $11 \%$ goalkeepers $(n=186), 35 \%$ defenders $(n=585)$, $34 \%$ midfielders $(n=579)$, and $20 \%$ forwards $(n=337)$. Anthropometric data for the included football players were $25 \pm 5$ years (range 16-44), with a height of $183 \pm 6 \mathrm{~cm}$ (range 166-200) and weight of 78 $\pm 7 \mathrm{~kg}$ (range 53-96).

Staff members from all 16 medical teams were initially contacted, between December 2016 and February 2017, and provided with oral and written information about the study.

All teams consented in writing to participate in the present study. Data regarding player and team characteristics (player position, age, height, weight and squad size) were collected through the website Elitefootball.com [10], which provides such data on the official website of the Swedish first football league [24]. All other data, such as total team exposure (training and playing time), injuries (time-loss), and absence days (days lost due to injury), were extracted from the Swedish National Injury Surveillance Database [30].

This injury surveillance database is used prospectively by medical teams in the Swedish first football league to report injuries and treatment of individual players. Injuries that cause time-loss are registered with an injury card, which follows the consensus on injury definitions and data collection procedures in football studies [11]. This reporting system enables extraction of data for statistical purposes and to design epidemiological studies on football injuries.

\section{Definitions}

All injuries sustained by a player during football play (training and/or match) and resulting in time-loss (a player being unable to participate fully in future training or match play) are defined as injury and should be registered in the Swedish National Injury Surveillance Database [30]. A recurrent injury is defined as an injury occurring after a player returns to full participation from an index injury of the same type and at the same site as the first injury [11]. In accordance with the consensus on injury definitions and data collection procedures in football studies, injury incidence is calculated as the number of injuries per 1000 exposure hours [11]. Injury burden is calculated as the number of days lost per $1000 \mathrm{~h}$ of exposure, according to Bahr et al. [5].

\section{Statistical analysis}

Collected data were analysed using Microsoft Excel 2016 ver. 15.33 (Microsoft Co. Redmond, WA, USA) and IBM SPSS Statistics ver. 24.0 (IBM Co. Armonk, NY, USA). Descriptive statistics are presented as frequency, percent, mean, standard deviation (SD), 95\% confidence interval ( $95 \% \mathrm{CI})$, median, interquartile range (IQR), and range. Inferential statistics were used when analysing incidence and burden between seasons. A one-way analysis of variance (ANOVA) was used to compare normally distributed data, and the Kruskal-Wallis $H$ test was used when data were not normally distributed. The significance level was set at $5 \%(p<0.05)$.

\section{Results}

In total, 467 time-loss injuries located to the hip/groin were recorded among 1687 professional football players. The total exposure (training and matches) for 59 team seasons was $566,145 \mathrm{~h}$, with a mean \pm SD of $9596 \pm 2362 \mathrm{~h}$ per season. As a result, injury incidence was $0.82 / 1000 \mathrm{~h}(95 \% \mathrm{CI}$ 0.71-1.01). Results did not reveal any significant differences between seasons $F(4,54)=1.42$, n.s. The median prevalence 
of time-loss injuries was 7.0 (IQR 4.5-11.0) per season per club, with an average of 29 players.

The overall injury burden was 15.6/1000 h (95\% CI 11.9-20.6). Results showed that there was no statistically significant difference in injury burden between seasons, $X^{2}(4)=5.401$, n.s., with a mean rank burden of 30.58 for the 2012 season, 37.30 for the 2013 season, 21.50 for the 2014 season, 33.38 for the 2015 season, and 28.17 for the 2016 season. The median day lost due to injury was 97 days (IQR 50-209) per season per club. Descriptive data regarding frequency, incidence, and burden are summarised in Table 1.

Characteristics of hip/groin injuries are presented in Table 2, and types of injuries in hip/groin are presented in Table 3.

Overuse mechanism was found to be the most frequent determining factor, with $28 \%$ injuries, followed by unknown mechanism (18\%), kicking (15\%), sprinting/running (13\%), and stretch situations (9\%) (Fig. 1). However, when looking at absence days from football play, the unknown mechanism was the most commonly observed (31\%), followed by overuse (27\%), sprinting/running (12\%), kicking (11\%), change of direction (7\%), and stretch situations (7\%) (Fig. 2).

\section{Player position}

Defenders sustained most hip/groin injuries, which also were the most severe ones, followed by midfielders, forwards, and goalkeepers (Table 4). However, when adjusting for the number of players in their respective positions, both defenders and midfielders sustained $29 \%$ each of the total injuries, but defenders alone sustained most of the absence days $(33 \%)$ (Table 4$)$.
Table 2 Characteristics of hip/groin injuries

\begin{tabular}{lcll}
\hline & Number & Percentage & Incidence/burden \\
\hline Injuries & & & \\
$\quad$ Overuse & 258 & 55 & $0.46^{\mathrm{a}}$ \\
$\quad$ Traumatic & 209 & 45 & $0.37^{\mathrm{a}}$ \\
Absence days & & & \\
$\quad$ Overuse & 6022 & 69 & $10.6^{\mathrm{b}}$ \\
$\quad$ Acute/trauma & 2719 & 31 & $4.8^{\mathrm{b}}$ \\
Injuries & & & \\
$\quad$ Index injuries & 402 & 86 & $0.71^{\mathrm{a}}$ \\
$\quad$ Recurrent injuries & 65 & 14 & $0.11^{\mathrm{a}}$ \\
Absence days & & & $12.8^{\mathrm{b}}$ \\
$\quad$ Index injuries & 7239 & 83 & $2.6^{\mathrm{b}}$ \\
Recurrent injuries & 1500 & 17 & \\
\hline
\end{tabular}

Percentage refers to the total number of injuries and absence days in this table

${ }^{\mathrm{a}}$ Incidence and ${ }^{\mathrm{b}}$ burden are presented as injuries and absence days/1000 h of exposure respectively

\section{Discussion}

The main finding in the present cohort study was that hip/ groin injuries do not seem to be an increasing phenomenon in the Swedish male first football league. In addition, index and overuse injuries accounted for the majority of injuries and absence days. Therefore, more attention should be paid to preventing hip/groin injuries to lower the injury rate.

Table 1 Frequency of hip/groin injuries in Swedish professional football

\begin{tabular}{|c|c|c|c|c|c|c|}
\hline Season & 2012 & 2013 & 2014 & 2015 & 2016 & Total \\
\hline No. of injuries & 94 & 76 & 78 & 118 & 101 & 467 \\
\hline No. of training injuries (\%) & $66(70 \%)$ & $53(70 \%)$ & $53(68 \%)$ & $79(67 \%)$ & $67(66 \%)$ & $318(68 \%)$ \\
\hline No. of match injuries (\%) & $28(30 \%)$ & $23(30 \%)$ & $25(32 \%)$ & $39(33 \%)$ & $34(34 \%)$ & $149(32 \%)$ \\
\hline No. of injuries per club ${ }^{\mathrm{a}}$ & $6.5(3.0-11.3)$ & $7.0(4.5-10.5)$ & $5.0(2.0-9.3)$ & $7.0(6.0-10.0)$ & $8.0(5.0-11.0)$ & $7.0(4.5-11.0)$ \\
\hline No. of absence days & 1889 & 2147 & 1146 & 2427 & 1234 & 8843 \\
\hline $\begin{array}{l}\text { No. of training absence days } \\
(\%)\end{array}$ & $1412(75 \%)$ & $1657(77 \%)$ & $914(80 \%)$ & $1977(81 \%)$ & $725(59 \%)$ & $6685(76 \%)$ \\
\hline No. of match absence days (\%) & $463(25 \%)$ & $490(23 \%)$ & $232(20 \%)$ & $360(15 \%)$ & $509(41 \%)$ & $2054(23 \%)$ \\
\hline No. of absence days per club ${ }^{\mathrm{a}}$ & $155(56-225)$ & $209(146-243)$ & $59(26-107)$ & $109(59-172)$ & $68(48-133)$ & $97(50-209)$ \\
\hline No. of exposure hours & 127571 & 110776 & 118759 & 112741 & 96299 & 566145 \\
\hline Incidence $^{\mathrm{b}}$ & $0.74(0.41-1.05)$ & $0.69(0.39-1.02)$ & $0.66(0.33-1.07)$ & $1.05(0.65-1.51)$ & $1.05(0.71-1.39)$ & $0.82(0.71-1.01)$ \\
\hline Injury burden $^{c}$ & $14.8(8.0-20.5)$ & $19.4(10.7-29.6)$ & $9.6(2.4-19.1)$ & $21.5(6.3-39.0)$ & $12.8(5.8-21.7)$ & $15.6(11.9-20.6)$ \\
\hline
\end{tabular}

${ }^{\text {a }}$ Data presented as median (IQR)

${ }^{\mathrm{b}}$ Incidence presented as injuries/1000 h of exposure (95\% CI)

${ }^{\mathrm{c}}$ Injury burden presented as absence days $/ 1000 \mathrm{~h}$ of exposure $(95 \% \mathrm{CI})$ 
Table 3 Injury type of hip/groin injuries

Fig. 1 Total number of injuries by each injury mechanism during the 2012-2016 seasons

Fig. 2 Total number of absence days by each injury mechanism during the 2012-2016 seasons

\begin{tabular}{lllll}
\hline & Injuries $n(\%)$ & Incidence & Absence days $n(\%)$ & Burden \\
\hline Muscle rupture/tear/strain/cramps & $278(60)$ & 0.5 & $3292(39)$ & 6.0 \\
Unspecific overuse symptoms & $113(24)$ & 0.2 & $3123(37)$ & 5.7 \\
Tendon injury/rupture/tendinosis/bursitis & $28(6)$ & 0.05 & $419(5)$ & 0.7 \\
Other injuries & $23(5)$ & 0.04 & $1407(16)$ & 2.5 \\
Contusion & $17(4)$ & 0.03 & $117(1)$ & 0.2 \\
Haematoma & $4(1)$ & 0.007 & $79(1)$ & 0.1 \\
Synovitis/joint swelling & $4(1)$ & 0.007 & $75(1)$ & 0.1
\end{tabular}

Percentage refers to the total number of injuries and absence days in this table

Incidence are presented as injuries/1000 h of exposure. Burden are presented as absence days/1000 h of exposure
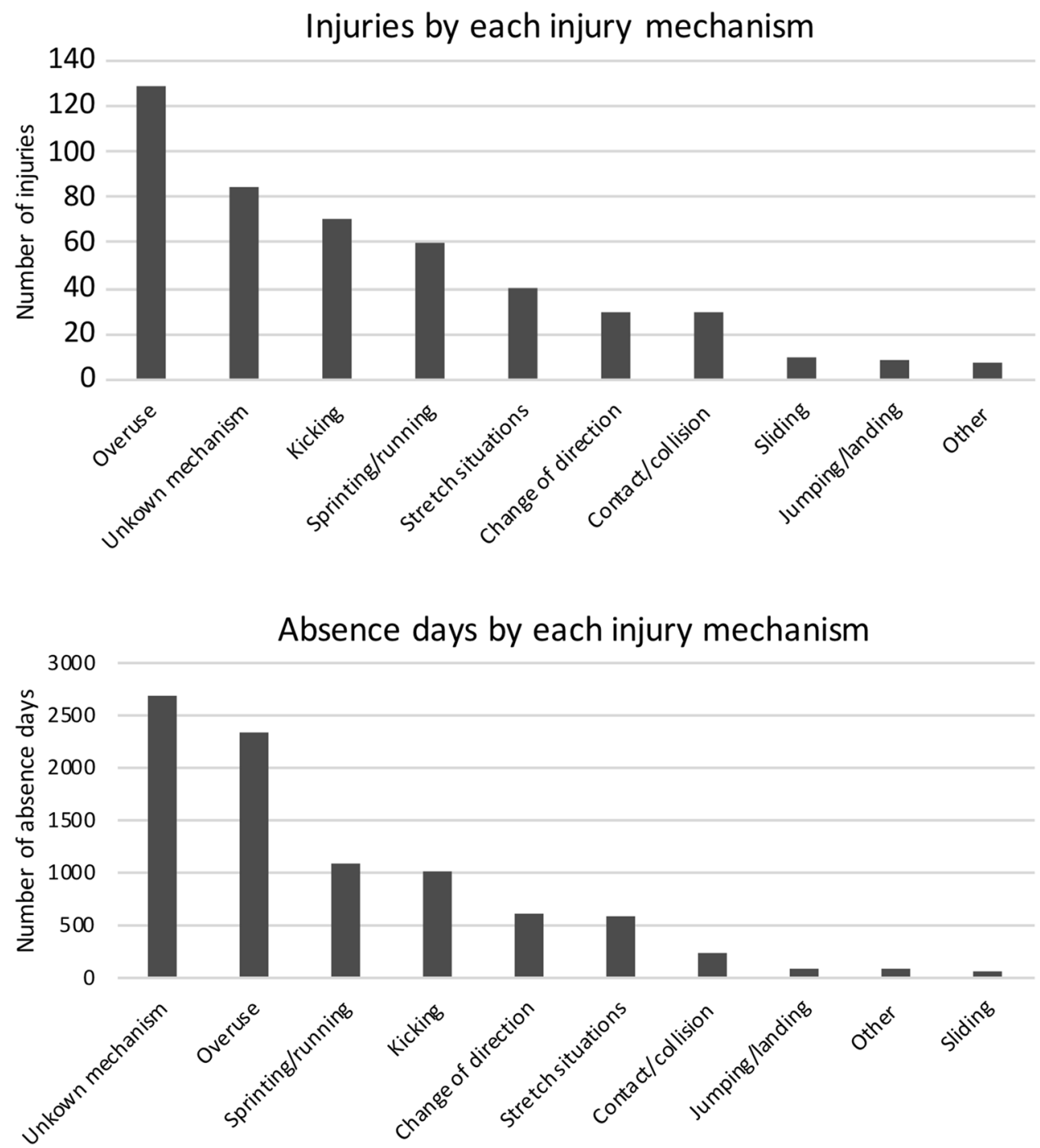

\section{Hip and groin injury epidemiology}

The total incidence of hip/groin injuries was $0.82 / 1000 \mathrm{~h}$, which is lower than the previous research from professional football in Sweden (range 1.0-1.3/1000 h) $[17,18]$ and the reported rate $(1.0 / 1000 \mathrm{~h})$ in the UEFA Elite Club Injury Study [37]. The incidence was, however, greater than those reported from Scandinavian sub-elite and amateur level [2, $9,20]$, which might suggest that hip/groin injuries tend to increase with higher level of play. One explanation for this 
Table 4 Injuries and absence days by position

\begin{tabular}{lcccc}
\hline & Injuries & Percentage $^{\mathrm{a}}$ & Absence days & Percentage $^{\mathrm{a}}$ \\
\hline Goalkeeper & 27 & 6 & 390 & 5 \\
Defender & 165 & 38 & 3387 & 41 \\
Midfielder & 160 & 36 & 2723 & 33 \\
Forward & 88 & 20 & 1682 & 21 \\
\hline
\end{tabular}

${ }^{\text {a}}$ Percentage refers to the number of injuries and absence days per position divided by the total number of injuries and absence days in this table

trend could be the heavier training and match load for the most successful teams in Europe, which play both domestic and international games such as in the UEFA Champions League and Europa League. Players from the best teams also tend to play for their national teams, which further increases their seasonal workload. Other factors that hypothetically might influence injury risk could be differences in tactics, climate, field surface, playing style, and match intensity. In addition, Waldén et al. [34] concluded that regional differences in injury epidemiology exist and should be considered when comparing football studies. However, there was a trend towards an increasing incidence over five consecutive seasons in the present study, with the injury rate being approximately 43\% higher during the last two seasons (2015-2016) than the initial three (2012-2014). However, this comparison did not reach statistical significance. This is an interesting finding, since it differs from the reported data in the UEFA Elite Club Injury Study, where the incidence was found to be slightly decreasing over a 15 -year period of time [37]. One potential reason for this sudden increase in incidence during the 2015 season could partly be explained by the publication of the consensus statement on hip/groin injury definitions and terminology the same year [35]. With a better understanding about diagnostic criteria, medical teams might have captured more injuries leading to an increase in incidence.

Nevertheless, when comparing seasonal incidence in the present study with the previous studies from professional male football in Sweden, the injury rate lies around 1.0 injury per 1000 exposure hours (range $0.7-1.3$, median 1.0) $[17,18]$. This suggests that the injury incidence is not an increasing phenomenon in Swedish professional male football over a longer period of time, and that seasonal changes happen more often due to natural variations. This is somewhat supported by Bjørneboe et al. [6] who found acute hip/groin match injury incidence to be fluctuating over six consecutive seasons in the Norwegian professional league, with approximately the same range (0.6-1.4) as earlier studies, including the present one, have reported $[17,18]$.

The seasonal burden was found to be more inconsistent (range 9.6-21.5 absence days) than the injury rate, and the present study could not present any increasing trend. Burden refers to the risk of absence from football play, which could vary depending on the severity of injuries. Like incidence, burden can also mean natural variations between seasons that hypothetically can depend on factors such as coaching philosophy, seasonal workload, and injury management.

Burden has not been a standard measure in earlier studies; therefore, there is limited research for comparisons. Thus, the overall injury burden of hip/groin injuries was $15.6 / 1000 \mathrm{~h}$ and is lower than the $24.3 / 1000 \mathrm{~h}$ found in Qatar's first league [23]. This difference could partly depend on the number of seasons investigated, where Mosler et al. [23] only studied two seasons compared to five in the present one. However, new data from Werner et al. [37] suggest that the injury burden in the Swedish first football league is almost the same as in the UEFA Elite Club Injury Study, where the rate is $16.1 / 1000 \mathrm{~h}$.

Recently published time-trend analysis of ankle and hamstring injuries in the UEFA Champions League makes it possible to compare injury risk with the hip/groin findings in the present study. The overall incidence and burden are slightly higher for both ankle $(1.0 / 1000 \mathrm{~h}$ and $16.3 / 1000 \mathrm{~h})$ [33] and hamstring injuries $(1.2 / 1000 \mathrm{~h}$ and $19.7 / 1000 \mathrm{~h})$ [8] compared to the results of hip/groin injuries $(0.8 / 1000 \mathrm{~h}$ and $15.6 / 1000 \mathrm{~h}$ ) in the present study. However, when comparing UEFA Champions League incidence between the different injury locations, injury rate is surprisingly consistent (hip/ groin $1.0 / 1000 \mathrm{~h}$, ankle $1.0 / 1000 \mathrm{~h}$, hamstrings $1.2 / 1000 \mathrm{~h}$ ) $[8,33,37]$, establishing hip/groin injuries as a substantial problem in professional football.

A considerably large amount of hip/groin injuries appear every season in Swedish professional football, and the true magnitude might be underestimated, because the current methodology only covers time-loss injuries [14]. Since football injuries seem to be the most common cause for players being unavailable for football activities during the competitive season [25] and can affect team performance negatively [19], teams are recommended to implement evidence-based preventive training exercises. One potential exercise that teams could consider is the Copenhagen hip adduction exercise due to its eccentric strengthening of the adductors [15, 21]. Teams should also be aware of the fluctuations in both incidence and burden, since these measures affect player availability and thereby team success [19].

\section{Injury characteristics}

The present study displayed a relatively low recurrence rate for hip/groin injuries (14\%) compared to the previous findings $[1,16,23,38]$, where injury rates have been found to vary between 15 to $50 \%$. The higher rates were primarily found in studies comprising rather small sample sizes or few seasons, which could partly explain the differences. Nonetheless, recently published data from the UEFA Elite 
Club Injury Study suggest that the recurrence rate is even lower (11\%) [37]. This may be related to greater investments in medical teams in Europe's top division teams that hypothetically would result in better care of players than at lower levels.

One can argue that recurrent injuries are a medical team issue, where players get a suboptimal rehabilitation and are forced into participating in football activities earlier than required.

The majority of hip/groin injuries in the present study are, however, a result of overuse and primarily affected muscles, as found in the other studies [20, 23, 38]. Overuse injuries are strongly related to drastic changes (spikes) in weekly workload and have lately been considered as a training load error [12], which could suggest that the seasonal workload is the main problem concerning hip/groin injuries in the Swedish first football league and needs to be managed better.

The findings in the present study of a high prevalence of unknown mechanism and overuse mechanism could, to some degree, be explained by the previous lack of consensus concerning terminology and taxonomy $[35,36]$. Implementation of these recommendations is strongly recommended to ensure correct diagnosis. Another issue could be the injury registration. If an injury appears during training and the medical staff are not around at the exact moment and the player cannot remember how the injury happened, it could end up as an unspecific or overuse mechanism during injury registration.

As for the specific mechanisms, kicking was the main cause of injury, while sprinting/running represents most of the absence days. These two risk factors have recently been associated with the main mechanisms in rectus femoris injuries [29], whereas kicking and change of direction seem to be the main risk factors for adductor longus strains [28]. Together with stretch situations, these four injury situations confirm the previous research as the key mechanisms in team sport athletes [26]. Further conclusions could not be stated in the present study and should be addressed in future studies.

The main strength of the present study is that the data collections were conducted prospectively over several seasons and include a substantial homogenous group of professional football players. In addition, data were obtained from an injury surveillance database, which is developed for statistical purposes, and follows the international consensus agreements on injury definitions and data collection procedures in epidemiological studies on football injuries [11]. Another strength is the implementation of injury burden that together with incidence illustrates a relationship between the consequence (burden) and the likelihood (incidence) of injuries [5]. Since the present study is only the third one to use injury burden as a measure of absence risk for hip/groin injuries in professional football, it could be used in the future to compare burden in football studies.

A clear limitation of the present study is the use of a time-loss injury definition that may underestimate the risk of overuse injuries $[4,14]$, which represents at least $50 \%$ of hip/groin injuries [20, 23, 37, 38]. Therefore, a combined method that captures "all physical complaints" is recommended, but, since the present study is epidemiological, it cannot demonstrate the cause-and-relationship effect. In addition, the present study does not present the overall injury rate, which would have been beneficial to conclude the extent of hip/groin injuries in the Swedish first football league. In addition, it would have been a strength if the present study reported hip and groin injuries separately, as these could be defined as two different anatomical areas. However, when combined, it makes it easier to compare with earlier studies, because this definition is still a consensus [11]. Furthermore, the present study does not report specific diagnosis or clinical entities, which would have been preferable, since a few studies have addressed this topic [32]. Finally, the results in the present study could potentially have been affected by missing data and inaccuracies in the data set. However, injury registration is done by professional medical teams and substantial guidelines are available, both within the injury surveillance database and through evidentially consensus recommendations [11].

\section{Conclusions}

The present study suggests that hip/groin injuries are a substantial problem in football, but does not seem to be an increasing phenomenon in the Swedish male first football league. Index and overuse injuries accounted for the majority of injuries and absence days. Risk factors include mechanisms such as kicking, sprinting/running, change of direction, and stretch situations, and being an outfield player. Medical and fitness staff should focus on strategies to prevent first-time injuries and overuse symptoms transforming into injuries to decrease the hip/groin injury rate.

Acknowledgements The authors express their sincere gratitude to Associate Professor Magnus Forsblad for access to the Swedish National Injury Surveillance Database.

Funding The authors received no financial support for the research, authorship, and publication of this article.

\section{Compliance with ethical standards}

Conflict of interest F. Lundgårdh, M.Sc., RPT, K. Svensson, M.Sc., RPT, and M. Alricsson, Ph.D, RPT declare that they have no conflict of interest. 
Ethical approval It was obtained from the Regional Ethical Review Board in Umeå, Sweden (2016/491-31), and the study was conducted in accordance with the Declaration of Helsinki for Human studies.

Open Access This article is distributed under the terms of the Creative Commons Attribution 4.0 International License (http://creativeco mmons.org/licenses/by/4.0/), which permits unrestricted use, distribution, and reproduction in any medium, provided you give appropriate credit to the original author(s) and the source, provide a link to the Creative Commons license, and indicate if changes were made.

\section{References}

1. Arnason A, Gudmundsson A, Dahl HA, Jóhannsson E (1996) Soccer injuries in Iceland. Scand J Med Sci Sports 6:40-45

2. Arnason A, Sigurdsson SB, Gudmundsson A, Holme I, Engebretsen L, Bahr R (2004) Risk factors for injuries in football. Am J Sports Med 32:5-16

3. aus der Fünten K, Faude O, Lensch J, Meyer T (2014) Injury characteristics in the German professional male soccer leagues after a shortened winter break. J Athl Train 49:786-793

4. Bahr R (2009) No injuries, but plenty of pain? On the methodology for recording overuse symptoms in sports. Br J Sports Med 43:966-972

5. Bahr R, Clarsen B, Ekstrand J (2018) Why we should focus on the burden of injuries and illnesses, not just their incidence. $\mathrm{Br} \mathrm{J}$ Sports Med 52:1018-1021

6. Bjørneboe J, Bahr R, Andersen TE (2014) Gradual increase in the risk of match injury in Norwegian male professional football: a 6-year prospective study. Scand J Med Sci Sports 24:189-196

7. Ekstrand J, Hägglund M, Waldén M (2011) Injury incidence and injury patterns in professional football: the UEFA injury study. Br J Sports Med 45:553-558

8. Ekstrand J, Waldén M, Hägglund M (2016) Hamstring injuries have increased by $4 \%$ annually in men's professional football, since 2001: a 13-year longitudinal analysis of the UEFA Elite Club injury study. Br J Sports Med 50:731-737

9. Engebretsen AH, Myklebust G, Holme I, Engebretsen L, Bahr R (2010) Intrinsic risk factors for groin injuries among male soccer players: a prospective cohort study. Am J Sports Med 38:2051-2057

10. (2018) Football statistics and transfer news in Swedish, Spanish, English, Italian and French professional football. http://www.elite football.com. Accessed 17 June 2018

11. Fuller CW, Ekstrand J, Junge A, Andersen TE, Bahr R, Dvorak $\mathrm{J}$ et al (2006) Consensus statement on injury definitions and data collection procedures in studies of football (soccer) injuries. Scand J Med Sci Sports 16:83-92

12. Gabbett TJ, Kennelly S, Sheehan J, Hawkins R, Milsom J, King E et al (2016) If overuse injury is a 'training load error', should undertraining be viewed the same way? Br J Sports Med 50:1017-1018

13. Griffin DR, Dickenson EJ, O’Donnell J, Agricola R, Awan T, Beck M et al (2016) The Warwick Agreement on femoroacetabular impingement syndrome (FAI syndrome): an international consensus statement. Br J Sports Med 50:1169-1176

14. Harøy J, Clarsen B, Thorborg K, Hölmich P, Bahr R, Andersen TE (2017) Groin problems in male soccer players are more common than previously reported. Am J Sports Med 45:1304-1308

15. Harøy J, Thorborg K, Serner A, Bjørkheim A, Rolstad LE, Hölmich $P$ et al (2017) Including the Copenhagen adduction exercise in the FIFA $11+$ provides missing eccentric hip adduction strength effect in male soccer players: a randomized controlled trial. Am J Sports Med 45:3052-3059

16. Hawkins RD, Fuller CW (1999) A prospective epidemiological study of injuries in four English professional football clubs. Br J Sports Med 33:196-203

17. Hägglund M, Waldén M, Ekstrand J (2006) Previous injury as a risk factor for injury in elite football: a prospective study over two consecutive seasons. Br J Sports Med 40:767-772

18. Hägglund M, Waldén M, Ekstrand J (2009) Injuries among male and female elite football players. Scand J Med Sci Sports 19:819-827

19. Hägglund $\mathrm{M}$, Waldén $\mathrm{M}$, Magnusson $\mathrm{H}$, Kristenson $\mathrm{K}$, Bengtsson H, Ekstrand J (2013) Injuries affect team performance negatively in professional football: an 11-year follow-up of the UEFA Champions League injury study. Br J Sports Med 47:738-742

20. Hölmich P, Thorborg K, Dehlendorff C, Krogsgaard K, Gluud $C$ (2014) Incidence and clinical presentation of groin injuries in sub-elite male soccer. Br J Sports Med 48:1245-1250

21. Ishøi L, Sørensen CN, Kaae NM, Jørgensen LB, Hölmich P, Serner A (2016) Large eccentric strength increase using the Copenhagen adduction exercise in football: a randomized controlled trial. Scand J Med Sci Sports 26:1334-1342

22. Junge A, Dvorak J (2004) Soccer injuries: a review on incidence and prevention. Sports Med 34:929-938

23. Mosler AB, Weir A, Eirale C, Farooq A, Thorborg K, Whiteley RJ et al (2018) Epidemiology of time loss groin injuries in a men's professional football league: a 2-year prospective study of 17 clubs and 606 players. Br J Sports Med 52:292-297

24. Official website of the Swedish first football league (Allsvenskan) (2018). https://allsvenskan.se/. Accessed 17 Jun 2018

25. Parry L, Drust B (2006) Is injury the major cause of elite soccer players being unavailable to train and play during the competitive season? Phys Ther Sport 7:58-64

26. Serner A, Tol JL, Jomaah N, Weir A, Whiteley R, Thorborg K et al (2015) Diagnosis of acute groin injuries: a prospective study of 110 athletes. Am J Sports Med 43:1857-1864

27. Serner A, van Eijck CH, Beumer BR, Hölmich P, Weir A, de Vos RJ (2015) Study quality on groin injury management remains low: a systematic review on treatment of groin pain in athletes. Br J Sports Med 49:813

28. Serner A, Weir A, Tol JL, Thorborg K, Roemer F, Guermazi A et al (2018) Characteristics of acute groin injuries in the adductor muscles: a detailed MRI study in athletes. Scand J Med Sci Sports 28:667-676

29. Serner A, Weir A, Tol JL, Thorborg K, Roemer F, Guermazi A et al (2018) Characteristics of acute groin injuries in the hip flexor muscles-a detailed MRI study in athletes. Scand J Med Sci Sports 28:677-685

30. Swedish National Injury Surveillance Database (2019) Svenskt Nationellt Skaderegister. https://skaderegister.se/. Accessed 17 Feb 2019

31. Thorborg K, Rathleff MS, Petersen P, Branci S, Hölmich P (2017) Prevalence and severity of hip and groin pain in sub-elite male football: a cross-sectional cohort study of 695 players. Scand J Med Sci Sports 27:107-114

32. Waldén M, Hägglund M, Ekstrand J (2015) The epidemiology of groin injury in senior football: a systematic review of prospective studies. Br J Sports Med 49:792-797

33. Waldén M, Hägglund M, Ekstrand J (2013) Time-trends and circumstances surrounding ankle injuries in men's professional football: an 11-year follow-up of the UEFA Champions League injury study. Br J Sports Med 47:748-753

34. Waldén M, Hägglund M, Orchard J, Kristenson K, Ekstrand J (2013) Regional differences in injury incidence in European professional football. Scand J Med Sci Sports 23:424-430 
35. Weir A, Brukner P, Delahunt E, Ekstrand J, Griffin D, Khan KM et al (2015) Doha agreement meeting on terminology and definitions in groin pain in athletes. Br J Sports Med 49:768-774

36. Weir A, Hölmich P, Schache AG, Delahunt E, de Vos RJ (2015) Terminology and definitions on groin pain in athletes: building agreement using a short Delphi method. Br J Sports Med 49:825-827

37. Werner J, Hägglund M, Ekstrand J, Waldén M (2018) Hip and groin time-loss injuries decreased slightly but injury burden remained constant in men's professional football: the 15-year prospective UEFA Elite Club Injury Study. Br J Sports Med. https:// doi.org/10.1136/bjsports-2017-097796
38. Werner J, Hägglund M, Waldén M, Ekstrand J (2009) UEFA injury study: a prospective study of hip and groin injuries in professional football over seven consecutive seasons. Br J Sports Med 43:1036-1040

Publisher's Note Springer Nature remains neutral with regard to jurisdictional claims in published maps and institutional affiliations. 